\title{
Effects of smartphone-based collaborative vlog projects on EFL learners' speaking performance and learning engagement
}

\author{
Hui-Wen Huang \\ Fujian University of Technology
}

\begin{abstract}
This study examined how smartphone-based collaborative video projects influenced English as a Foreign Language (EFL) learners' speaking performance and learning engagement using blended learning in China. The collaborative video projects helped students engage in two smartphone-based video filming tasks to combine language learning with real-life experiences simultaneously. A total of 65 college students used smartphones to participate in 3-minute collaborative video tasks that were related to the learning context of the classroom textbook. Qualitative and quantitative data were collected during this 8-week intervention. This included pretest and post-test speaking scores, a questionnaire on group collaboration, students' final reflections and focus group interviews. A paired-sample t test, descriptive analysis and qualitative content analysis were used to analyse the data. The results indicate that students' speaking abilities were significantly improved at the end of the intervention. They enjoyed group collaboration in the video projects and appreciated acquiring digital media production skills. Interview results highlight the opportunities for and challenges of the educational application of video projects in EFL classrooms.
\end{abstract}

Implications for practice or policy:

- Integrating collaborative vlog projects in EFL classrooms can stimulate students' speaking performance.

- Student-made collaborative vlogs can help students develop 21st century skills, especially in digital media production.

- Smartphone-based vlog projects can increase learners' engagement and enhance their group collaboration skills.

Keywords: vlog projects, mobile-assisted language learning, English as a Foreign Language (EFL) teaching, speaking performance, group collaboration, mixed-method design

\section{Introduction}

Smartphones have become increasingly integrated into educational settings. With the global migration to online learning, the important role that mobile technology now plays in teaching and learning is in need of further investigation (Gromik, 2012, 2015). Smartphone technology allows students to take pictures, film videos, make audio recordings, listen to music, watch multimedia material, use educational applications or software (Kim \& Kwon, 2012; Nami, 2020), send text messages and communicate with friends and family members. Among these features, the built-in audio-video recording function on smartphones can be integrated effectively with learning activities to provide enhanced educational benefits and additional support as a language-learning tool in education. Thus, designing collaborative video projects using smartphones in EFL classrooms has the potential to increase group participation, develop social skills in communication and provide a sense of achievement in their filmmaking accomplishments.

When integrating video projects into English as a Foreign Language (EFL) classrooms, teachers can help students access, analyse, evaluate and create useful messages and content to develop media literacy skills, which are essential in the 21st century media world (Larson \& Miller, 2011; Shih, 2010; Sousa, 2017; Yang $\& \mathrm{Wu}, 2012$ ). Students can create learning material to express their ideas via various media, such as audio, videos, photos and digital documents. Earlier studies found that video projects enhance students' learning motivation and interests (Anas, 2019; Kirkgöz, 2011; Park, 2019; Shih, 2010) and increase their learning self-efficacy (Gromik, 2012, 2015; Hung, 2011). In other project-based learning environments, video projects were found to provide greater authentic learning opportunities (H. C. Huang, 2015; Meyer \& Forester, 2015) and improve EFL students' learning performance (Encalada \& Sarmiento, 2019; Yang \& $\mathrm{Wu}, 2012$ ). These learning benefits could be attributed to the sociocultural benefits of collaborative learning. 
Collaborative learning has a positive effect on language learning, which consequently creates a dynamic learning environment, and supports student motivation and positive attitudes towards-earning in general, resulting in increased knowledge construction (Nussbaum et al., 2009; Yang \& Wu, 2012). The application of group collaboration to support teaching and learning has been examined in previous studies (Lai et al., 2016; Nussbaum et al., 2009; Yang \& Wu, 2012). Students experienced more interaction with their group members in a technology-mediated learning environment (Huang et al., 2012; Nussbaum et al., 2009). While implementing video projects, students engaged in group tasks enjoyed the process of technology application and developed their confidence in exhibiting their creativity with group members (Anas, 2019; Kim \& Kwon, 2012; Lai et al., 2016; McKenney \& Voogt, 2011; Scott, 2015).

The present study centred around the design of a video blog (vlog) projects, consisting of task-based activities arranged in order to meet the six criteria for computer-assisted language learning task appropriateness (Chapelle, 2001). These six criteria (i.e., language-learning potential, learner fit, meaning focus, authenticity, positive impact and practicality) are appropriate in assessing the vlog projects in order to evaluate the effectiveness of combining classroom learning and real-life experiences. Additionally, it is critical to use quantitative and qualitative data to explore the full potential for smartphone-based collaborative vlog projects in EFL learning and their impacts on students' language performance in English classes (Oskoz \& Elola, 2016). This study, therefore, bridges the research gap by employing a mixedmethod design to examine the effectiveness of collaborative vlog projects in EFL learners' speaking performance and learning experiences.

\section{Literature review}

Effective learning occurs when students have meaningful conversation and interaction with others in a shared experience under the instruction of a facilitator or in collaboration with capable peers, an important concept of social constructivism (Vygotsky, 1978). The integration of vlog projects supports the learning goals and provides EFL learners with the opportunity to apply the knowledge acquired in classes to realworld workplaces (Hung, 2011). Through student-generated video filming learning projects, students are able to transform textbook knowledge into creative products with digital media literacy, problem-solving, collaboration and creativity, all of which align with 21 st century skills in a changing world (Niemi \& Multisilta, 2016; Oskoz \& Elola, 2016; Park, 2019; Perry, 2018; Sousa, 2017).

\section{Social constructivism}

Vygotsky $(1978,1986)$ believed that social constructivism focuses on the social, cultural mechanisms of learning and knowledge construction. Social constructivism was developed from sociocultural theory, emphasising the mutual effect between people and the culture in which they live. It also states that human learning is, to a large extent, a social process. The process of social interaction can stimulate students' cognitive growth within their zone of proximal development (ZPD) in order to maximise learning achievements (Chaiklin, 2003; Nussbaum et al., 2009). Hence, it is crucial for teachers to design appropriate course materials and learning experiences to facilitate students' ZPD in the classroom.

Social constructivism is, first and foremost, the theory of knowledge focused on the role of social processes in knowledge construction. Learning occurs because results emerge from group interactions in a meaningful way. Its proponents are interested in the interaction among people which is observed as shared knowledge is constructed (Nussbaum et al., 2009; Vygotsky, 1978). Hence, students engage in collaborative activities to negotiate meaning and build new knowledge with others. In the constructivist understanding of teaching and learning, the focus moves from a teacher-oriented to a student-oriented learning approach, and learners' autonomy, together with their social interaction, become the central parts of educational settings (Morris, 2011). The teacher no longer plays a dominant role in delivering knowledge but acts as a mentor and facilitator (see Withall, 1975, for detailed examples and criterion) for students as they construct knowledge through active learning and social support. 


\section{Collaborative learning in education}

In recent years, collaborative learning in educational settings has become increasingly popular (Lai et al., 2016; Nussbaum et al., 2009; Schultz \& Quinn, 2013; Yang \& Wu, 2012). Collaborative learning highlights that knowledge construction is the result of active interactions among learners with each other. Learning occurs when individuals involve in a process of peer negotiation from a social-cultural context, a tenet of social constructivism theory (Morris, 2011; Mulligan \& Garofalo, 2011; Vygotsky, 1978). During the collaborative learning process, students share their experiences and discoveries with peers. Students can combine individual and team efforts to complete more challenging tasks and successfully develop social skills and accountability (Mulligan \& Garofalo, 2011; Schultz \& Quinn, 2013). Learning is not only an individual's process of gaining knowledge but also an interactive process that takes place within the community. Students become active learners in building knowledge for themselves through interactions with each other and with their surroundings. Students work together in teams with each other's contributions in order to reach a common goal and complete the assigned learning task (Anas, 2019; Lai et al., 2016; McKenney \& Voogt, 2011; Morris, 2011; Nussbaum et al., 2009).

Through group collaboration activities, students' cognitive development levels can be boosted under the help of more capable peers, and they can demonstrate their potential skills through social interactions with others (Chaiklin, 2003; Huang et al., 2012; Vygotsky, 1978). When students have opportunities like these to engage in learning tasks, they can advance their ZPD and accomplish the desired learning goals, which they could not otherwise complete by themselves. Collaborative learning in small groups provides students with external supports because they can learn different strengths from others and mutually help each other (Lai et al., 2016; Mulligan \& Garofalo, 2011). In the context of EFL learning, combining social constructivism and group collaboration in the design of a course can result in meaningful learning through students' teamwork and the exchange of ideas (H. W. Huang et al., 2020; Yang \& Wu, 2012).

\section{Video projects in EFL learning}

Technology has become widely adopted in the EFL classroom since the 1980s (Kilickaya, 2006; Warschauer, 1996a, 1996b); it has presented many positive effects on facilitating language learning and teaching (Gromik, 2015; H. C. Huang, 2015; Hung, 2011; McKenney \& Voogt, 2011; Shih, 2010; Yang \& $\mathrm{Wu}, 2012)$. In particular, students' self-produced video projects are popular among EFL learners. Through collaborative video projects, students develop communicative competence and experience authentic learning under meaningful interaction, which are vital elements of successful language learning and teaching (Anas, 2019; Council of Europe, 2001).

Since the early 2010s, researchers have applied vlog projects in language learning and shown their educational benefits in EFL classrooms (Aldukhayel, 2019; Encalada \& Sarmiento, 2019; Gromik, 2012, 2015; Hung, 2011; Yang \& Wu, 2012). Vlogs are made by people who use mobile devices or smartphones with video camcorder capabilities to film videos and upload them to online video platforms for audiences to watch (Snelson, 2015). For example, Hung's (2011) study indicated that vlog projects could serve as an assessment tool to monitor students' language development during the learning process, and his students reported positive attitude towards vlogging in classrooms. Yang and Wu (2012) employed a quasiexperimental design to explore the impact of video projects on students' English performance. Their participants significantly increased their academic achievement in listening, reading and writing, but no test was given for students' speaking performance. In a separate video-project study, H. C. Huang (2015) explored students' Test of English for International Communication (TOEIC) listening and reading proficiency as well as motivation in English learning. Huang found that post-test scores in listening and reading were significantly higher than pretest scores, and the TOEIC scores of the low proficiency group improved the most (H. C. Huang, 2015, p. 60). Her students also appreciated that the video project helped them speak English with confidence and increase their motivation to use the target language to express their thoughts in the video tasks.

In another study, Encalada and Sarmiento (2019) reported that students expanded their vocabulary, increased pronunciation accuracy and became more confident in their ability to speak English through selfrecording video. Kirkgöz's (2011) students not only expanded their vocabulary knowledge but also enhanced their oral skills (i.e., fluency, pronunciation, vocabulary, accuracy and task accomplishment) after utilising video-recorded speaking tasks. Students reported that they enjoyed a sense of achievement, and 
the video or vlog projects enhanced class engagement in terms of English learning (Aldukhayel, 2019; Gromik, 2012, 2015). Finally, video-producing projects can help to improve literacy proficiency (McKenney \& Voogt, 2011; Yang \& Wu, 2012), enhance students' social skills while interacting with peers (Park, 2019), and promote active learning (Anas, 2019).

In line with the theoretical frameworks of social constructivism and collaborative learning, students in collaborative vlog projects can work and engage in a learning community with peers to show positive effects on educational performance. An interactive learning community is based on students' meaningful communication in order to stimulate active and authentic learning (Mulligan \& Garofalo, 2011; Schultz \& Quinn, 2013). This type of learning community is beneficial for students in developing relationships with peers, which provides students with the opportunities to construct knowledge through group collaboration. Hence, learners can perform collaborative vlog projects within social interaction to share ideas and construct new knowledge (Vygotsky, 1978, 1986).

\section{1st century skills development through video projects}

Since 2000, the term 21st century skills has drawn the attention of many educators for supporting successful teaching and learning (Larson \& Miller, 2011; Niemi \& Multisilta, 2016; Perry, 2018; Schleicher, 2012; Scott, 2015; Sousa, 2017; Trilling \& Fadel, 2009). The Partnership for 21st Century Learning, part of Battelle for Kids in Ohio, United States of America, identified the 4Cs of 21st century skills: creativity, collaboration, communication and critical thinking; these four skills are critical for succeeding in $21 \mathrm{st}$ century work and life as well as tackling uncertain challenge in an increasingly complex world (see Figure 1). Trilling and Fadel (2009) claimed that students need to master three sets of skills in the 21 st century: learning and innovation skills, information, media and technology skills, as well as life and career skills (p. 48). Larson and Miller (2011) identified three core 21 st century skills that can be integrated in the classroom - communication and collaboration; expertise in technology; innovative thinking and problem-solving - in order to reshape instruction to meet the needs of the future changing world.

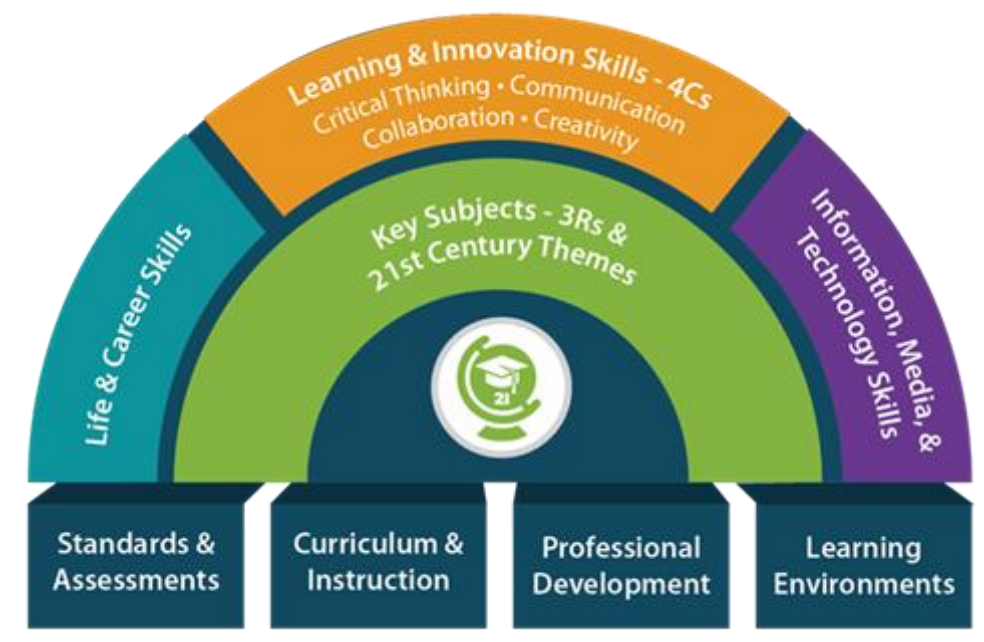

Figure 1. 21st century learning framework (Battelle for Kids, 2019, p. 1)

A common definition of 21st century skills includes creativity, communication and collaboration, critical thinking abilities and digital media literacy (Battelle for Kids, 2019; Larson \& Miller, 2011; OECD, 2015; Perry, 2018; Schleicher, 2012). In Bloom's revised taxonomy, critical thinking and creativity are identified to be higher-order thinking skills (Anderson et al., 2001; Sousa, 2017). The creative skills shown at the top of Bloom's revised taxonomy can be accomplished through technology (Churches, 2008; Niemi \& Multisilta, 2016; Sousa, 2017). It is essential for teachers to realise how digital media can empower students to become active learners and transfer their existing knowledge to a new task in order to develop their cognition and higher-order thinking skills (Park, 2019; Schultz \& Quinn, 2013; Sousa, 2017). Hence, students possessing 21st century skills can experience meaningful learning by increasing their ability to think critically and show their creativity in the transformation of learning (Sousa, 2017; Trilling \& Fadel, 2009). 
Studies have reported the benefits of integrating video projects in education to stimulate students' cognitive and emotional development as well as the 21st century skills development (Anas, 2019; Encalada \& Sarmiento, 2019; Niemi \& Multisilta, 2016; Perry, 2018; Shih, 2010). The design of video projects in group learning helps students develop collaboration, communication and critical thinking skills to solve problems they encounter during the process of video making (Yang \& Wu, 2012). Students can demonstrate their creative skills in video plot development after discussing and negotiating with peers (Niemi \& Multisilta, 2016). The process of video-making tasks allows students to actively engage in learning and stimulate their motivation to complete the multimedia projects (Schultz \& Quinn, 2013). Perry (2018) indicated that designing student-created video projects was helpful for students to develop multimedia skills needed in the 21 st century, such as problem-solving, decision-making and collaboration. Instead of merely being passive text readers, students who engage in video-making tasks can develop their potential and confidence in learning (Niemi \& Multisilta, 2016). Moreover, Oskoz and Elola (2016) indicated that the integration of task-based projects, such as digital storytelling or video projects, enables students to produce sophisticated digital media literacy, which is also an important skill in the 21 st century.

Applying technology in learning could support social constructivism and collaborative learning to boost students' learning quality (H. W. Huang et al., 2012; Niemi \& Multisilta, 2016; Perry, 2018). In Vygotsky's $(1978,1986)$ social constructivism theory, the concept of ZPD is a dynamic learning process in which students can achieve academic success through working with others and creating a context of shared meanings with peers. While working on smartphone-based collaborative vlog projects, students are able to develop social skills and higher-order thinking skills to boost their ZPD and knowledge acquisition. Meanwhile, their positive emotions, such as confidence and enjoyment, are heightened, and their negative emotions (i.e., anxiety and shyness) are lowered. The collaborative process of making vlogs helps students develop 21st century skills and engage in learning (Niemi \& Multisilta, 2016; Perry, 2018; Scott, 2015). Finally, students will gain a better understanding of the learning content in the textbooks and develop higher-order thinking levels - essential steps for meaningful learning (Churches, 2008; H. C. Huang, 2015; OECD, 2017). Such involvement leading to transformative learning helps the new learning enter the students' long-term memory and promotes retention (H. C. Huang, 2015; Park, 2019; Sousa, 2017).

\section{Research gap and research questions}

As shown in previous studies, integrating video projects in EFL learning has become an effective teaching approach in educational contexts (Aldukhayel, 2019; Anas, 2019; Encalada \& Sarmiento, 2019; Gromik, 2012, 2015; H. C. Huang, 2015; Hung, 2011; Park, 2019; Yang \& Wu, 2012). However, studies to date have mainly focused on students' perceptions, learning attitudes, language input skills (reading and listening) and writing skills. There is little empirical evidence on speaking performance in EFL learning using vlogs. Research focused on student-generated collaborative vlogs using smartphones for EFL speaking skills development is scarce. Previous studies neither explored the impact of collaborative vlog projects on English speaking skills nor examined students' perceptions of group collaboration in vlog making. H. C. Huang (2015) suggested that the effects of collaborative video learning should be investigated. Hung (2011) and Gromik (2015) also indicated that the impact of student-produced videos on language output skills is needed. To fill in the research gap, this study implemented smartphone-based collaborative vlog projects in an EFL class in China to investigate EFL learners' speaking performance, their perceptions of group collaboration and their learning experiences.

The study posed the following questions:

1. Are there any significant differences between the pretest and post-test speaking test results?

2. What are students' perceptions of group collaboration in the smartphone-based collaborative vlog projects?

3. How do the students perceive the learning experiences of smartphone-based collaborative vlog projects in their final reflections?

4. According to students' interviews, what are the opportunities and challenges in the process of smartphone-based collaborative vlog projects in English learning? 


\section{Methods}

\section{Research design}

This study employed a mixed-method research design utilising multiple sources of data collection to explore the effects of smartphone-based collaborative vlog projects on EFL learners' speaking outcomes and their learning experiences. All of the participants had the same opportunities to participate in the multimedia learning tasks using mobile devices to engage in the technology-supported instructional design in English classes. The study therefore did not use quasi-experimental design, that is, experimental and control groups, to examine intervention results. All the research questions, as well as quantitative and qualitative data collection are illustrated in Figure 2.

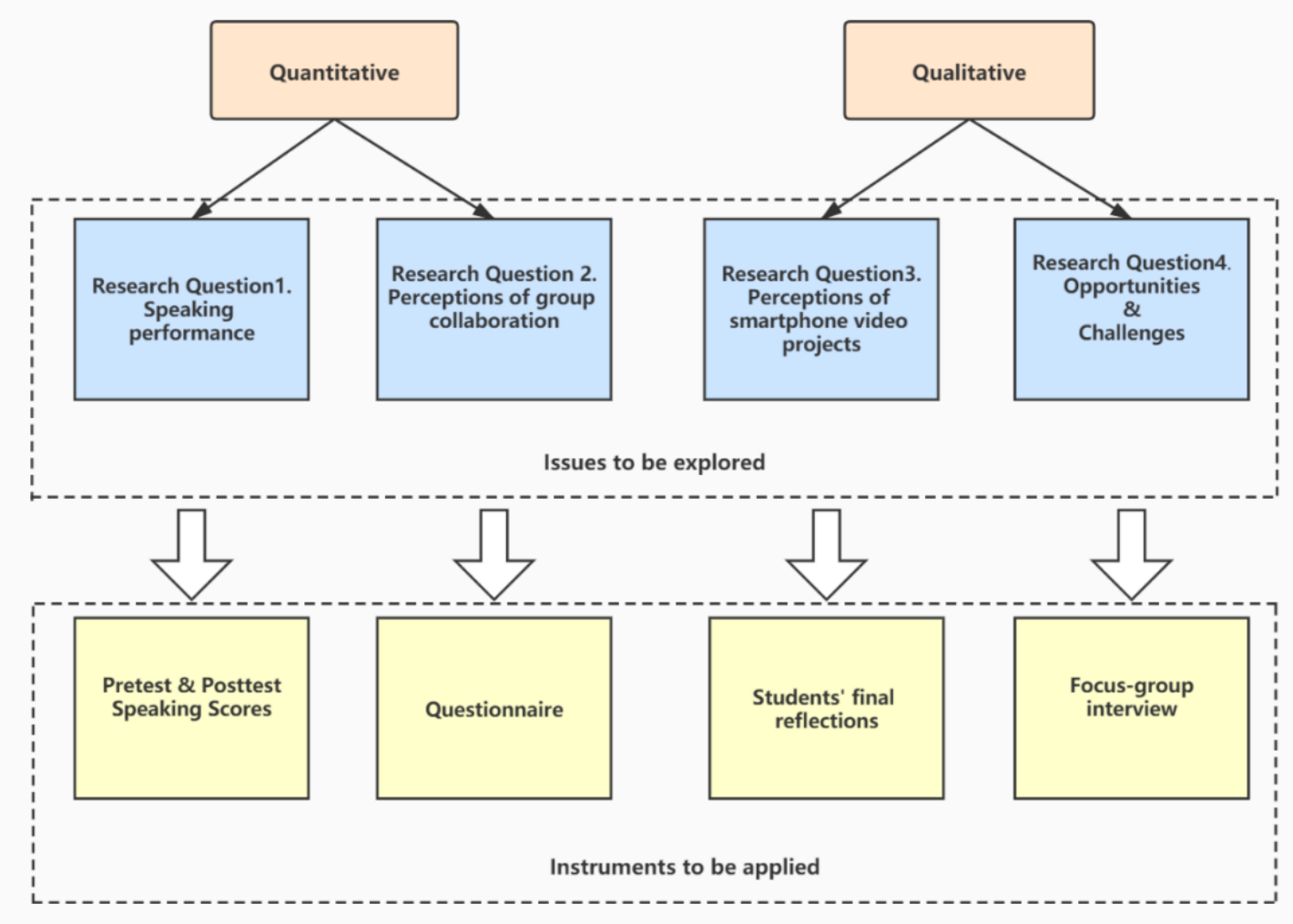

Figure 2. Research questions and instruments

\section{Participants}

The participants ( $N=65 ; 56$ females and 9 males) were translation major sophomores (aged 20-21 years) enrolled in a 4-year public technical university located in Fujian, China. The participants were divided into 16 groups of four or five students each, using a random grouping website. This study utilised a convenience sample as all the participants were enrolled in a blended learning course named Sophomore English. Chinese is the participants' primary language, and they were assessed to be intermediate English-level proficiency (i.e., according to English scores of the National College Entrance Examination in China (http://gaokao.neea.edu.cn/). Each participant had learned English and computer skills in formal education in the Chinese school system for at least 7 years prior to enrolling in this class. None of the participants, however, had any experience with recording and editing vlogs prior to this class.

Before the study, I announced the objective of the vlog projects to the participants. I then informed them that they had the right to withdraw at any time without any adverse effects on their final scores. Finally, participants indicated their permission by signing the consent forms. 


\section{Instruments}

A mixed-method study design was employed to collect comprehensive data, including pretest and post-test speaking tests, a group collaboration questionnaire, students' final reflections and semi-structured focus group interviews, for answering research questions. Two quantitative assessments were used: the TOEFL iBT independent speaking test followed by a questionnaire (Lai et al., 2016). The question format of the old TOEFL iBT independent speaking test was employed for the pretest and post-test.

At the 9th week of this project, students answered a 7-item questionnaire (see Table 2), adapted from Lai et al. (2016), regarding their perceptions of group collaboration with respect to the collaborative vlog projects. Lai et al. (2016) reported high reliability from Cronbach's alphas of 0.83 for enjoyment on collaboration (Questions $1 \&$ 2), 0.60 for attitudes towards collaboration (Questions $3 \& 4$ ) and 0.92 for perceived learning for collaboration (Questions 5-7). Among the 7 question items, Questions 3 and 4 were negatively worded items. The purpose of designing the negatively worded items was to minimise response bias and reduce a serious threat to the validity of self-reported surveys (Baumgartner \& Steenkamp, 2001). A 5-point Likert-type scale (ranging from 1 strongly disagree to 5 strongly agree) was provided for participants to indicate their perceptions. The questionnaire was originally published in English. Therefore, my research assistants and I translated the questionnaire into Chinese. To assess the validity of the translation and verify the content, I invited two bilingual English professors to review the translations. Three senior college students who were not involved in this study reviewed the Chinese translation to crosscheck for clarity and understanding.

Qualitative data was collected from final reflection papers and focus group interviews. These data were used to triangulate the findings collected from the quantitative data mentioned earlier. Final reflection papers collected students' thoughts regarding the vlog projects in English learning, and compared their previous learning experiences with the conventional instructional approach to the new experiences on vlog filming. A semi-structured focus group interview was conducted to understand the students' points of view about their overall learning experiences in the vlog projects. The interview was chosen because it provides in-depth information regarding students' attitudes and feelings, which can enrich the results from quantitative findings (Williams \& Katz, 2001). Moreover, Nyumba et al. (2018) claimed that focus group interviews can "yield more insights than the equivalent number of individual interviews" (p. 29). It is a group-based dynamic process of sharing and interacting between interviewees and interviewers. Furthermore, focus group interviews are useful for supporting quantitative data in exploring student learning experiences, learning attitude and academic achievement for triangulation purpose (Tashakkori \& Teddle, 2002). The interview questions explored the opportunities and challenges in vlog filming along with suggestions on how the vlog projects could be improved in terms of video content and learning activities.

\section{Procedures}

The students met for a 90-minute class period per week for 10 weeks over the intervention period. The two smartphone-based vlog projects were completed through group collaboration. The vlog topics were chosen from the textbook units, following the course syllabus. The two selected topics, Work-family balance and Chinese food culture, were related to students' daily life, and the students could apply the acquired linguistic skills in the classroom to project-based learning in real life. This helps students experience meaningful learning and make connections between the textbook content and daily life experience. Students implemented the two vlog projects using their smartphones. The smartphones are capable of capturing, editing and sharing videos using available video-editing applications (e.g., iMovie or PowerDirector). Students had 2 weeks to discuss the topics of the vlog projects, negotiate their opinions, film videos using their smartphones at the self-selected site, edit the videos, and upload the video clips to the class learning management system (i.e., Schoology). Afterwards, students had 1 week to watch and give comments on peers' vlogs.

To examine students' speaking performance, I used speaking pretest and post-test to collect data. Before the pretest, the participants had time to familiarise themselves with and practise two questions in class. For the pretest, I first announced the speaking questions (the independent TOEFL iBT speaking questions) and allocated 30 seconds for students to organise their answers. Once the 30 seconds were up, they recorded their answer as a 45-second audio file on their smartphones. For the post-test, they were required to follow the same test procedures as in the pretest. All the speaking questions are referred to as "personal choice", 
where the students are asked their opinion about a short statement or a given situation, for example, "What is your favourite season of the year?" or "Describe the most embarrassing moment in your life", similar to those appearing in the Speaking section of the TOEFL iBT test (Educational Testing Service, n.d.). The speaking test question in the post-test was different from that-in the pretest, but similar to the test topics.

After completing the two vlog projects, the students answered a questionnaire about vlog group collaboration in the class and completed final reflection papers regarding the smartphone-based vlog projects after class. The students completed the take-home reflection assignment over 1 week; however, they were given more time to elaborate on their answers if they desired. Six volunteers attended the semistructured focus group interview, answering questions about opportunities, challenges and suggestions in vlog projects for English learning. Two research assistants (RAs) conducted the focus group interviews after I provided a 2-hour interview training session including moderators' facilitation skills, further clarification skills without any bias or judgement and group interaction skills (see McConnell-Henry et al., 2010; Stewart et al., 2007). I was not involved in the interview as I wanted to avoid researcher influence, bias, or role conflict (i.e., the hierarchical relationship between the researcher (instructor) and the students) and eliminate any possibility that the interviewees might express opinions to please the instructor (Stalmeijer et al., 2014). The two RAs and the six volunteers had a pre-existing relationship; therefore, they were suitable for conducting the focus group interview. They provided a safe, comfortable context where the interviewees could feel secure and confident in disclosing their deeper thoughts (McConnell-Henry et al., 2010).

I created a semi-structured interview protocol to guide the interview processes (see Appendix A). This process utilised open-ended interview questions to examine both positive and negative responses (Glanz et al., 2008) regarding students' learning experiences of participating in the group vlog projects. The two RAs, serving as moderators, and six interviewees (one male, five females) logged into an online conferencing platform, Zoom (http://zoom.us), to conduct synchronous interviews. All the interviews were recorded after obtaining permission from the interviewees. The interview protocol was provided to the six interviewees prior to the interview for preparation, and the two moderators could guide any emerging discussions. The interview questions were written in English, but the interviews were conducted in Chinese in order to help the interviewees better express their feelings and opinions in their native language. The interview lasted 40 minutes. The participants were required to first state their roles and responsibilities in the vlog projects, along with responding to the following: the opportunities they experienced from the vlog projects; the challenges they observed from the vlog projects; and their suggestions concerning how the vlog projects could be improved in the future course design. The focus group interview process was recorded and later transcribed by the two RAs.

The completed experimental procedure allowed the quantitative data, including the speaking test and questionnaire, to explore the participants' speaking performance and their perceptions of group collaboration. Meanwhile, the qualitative data (i.e., the students' final reflection papers and the focus group interview) provided an in-depth understanding of how the students perceived the vlog projects and their inner thoughts. I gave feedback on each group's performance and drew conclusions from students' participation. Because the students already understood the content of the lessons and had obtained the instructional scaffolding to maximise their learning, they were assigned to complete the group vlog projects. My role in this study was as a facilitator and mentor (i.e., the theoretical framework stipulated a studentcentred learning environment). Students involved in an engaged learning process and completed the assigned tasks. If they encountered any problems, I provided them with the necessary support and solutions to continue the task. The experimental procedure is presented in Figure 3. 


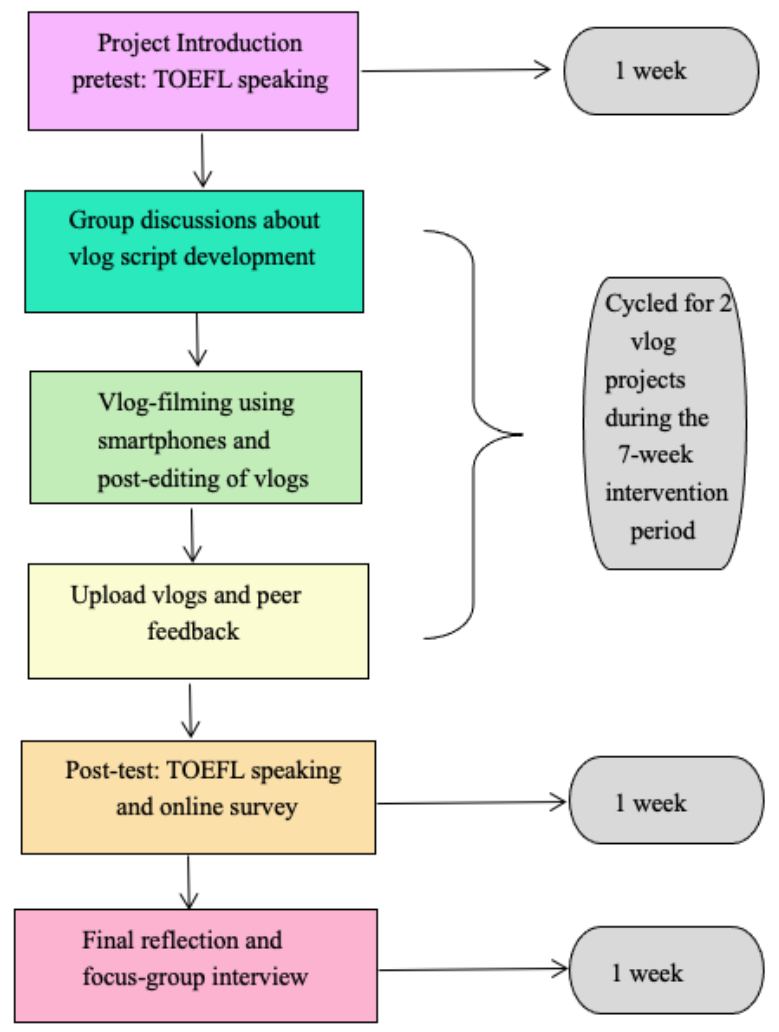

Figure 3. The experimental procedure

\section{Data analysis}

Two raters with at least 3 years' EFL teaching experiences in colleges separately assessed students' speaking pre- and post-test performance. The raters followed the TOEFL independent speaking scoring rubric (Educational Testing Service, 2019). In general, the rubric lists four categories for assessing speakers' speaking performance: general description, delivery, language use and topic development. The full score for question 1 of the TOEFL independent speaking test is 16, showing the greatest fluency and coherence in speaking. The lowest score is zero, which indicates that the student made no attempt to respond or provided off-topic responses. Percentiles would be easy for the researcher to understand students' overall performance for the old TOEFL iBT Speaking Question 1 section. All the scores were evaluated by the percentile value. The scores were multiplied by six to obtain the scores of 0-96 based on a 100-point scale.

Data collected from the speaking tests were analysed using a paired-sample $t$ test to compare the differences in the mean scores of the pretest and post-test, indicating students' speaking performance to answer Research Question (RQ) 1. The inter-rater reliability for grading students' speaking tests between the two raters was calculated. The inter-rater Cronbach's alpha coefficient was .81 at $p<.01$, indicating a high agreement between the two raters. The quantitative data from the questionnaire on group collaboration were analysed with SPSS version 25 to answer RQ2. Descriptive statistics, mean scores and standard deviations were calculated for students' perceptions of vlog group collaboration over the intervention period.

For the students' final reflections, students' answers were categorised by the RAs into different themes to understand students' learning experiences of vlog projects in order to answer RQ3. After I provided them with 2 hours of content analysis training, the two RAs read through all reflection texts twice. Following the content analysis procedures proposed by Braun and Clarke (2006), I conducted the six steps to analyse students' final reflection papers: (a) familiarising yourself with your data, (b) generating initial codes, (c) searching for themes, (d) reviewing themes, (e) defining and naming themes and (f) producing the report (p. 87). The first three steps $(\mathrm{a}-\mathrm{c})$ were completed separately by the RAs. Once they finished these steps, I examined the codes and emergent themes. To improve inter-rater reliability, the RAs and I reviewed the 
identified themes and students' reflection statements together to ensure the correctness of the emergent themes (steps d \& e). Where there was disagreement on creating themes, we reached consensus after discussion.

The data collected from the focus group interviews was translated from Chinese to English for coding and analysis. I checked the translation transcripts, completed by the two RAs, for accuracy by watching the recorded interview videos. The interview transcripts in English were analysed using an online service provider, WordClouds (http://www.wordclouds.com), a visual representation-generated tool to show the frequency of words displayed. WordClouds highlights the main ideas by presenting the most frequently written word in the text. This is one of the technologies to be utilised for research qualitative analysis in different educational contexts (Bletzer, 2015; DePaolo \& Wilkinson, 2014; Jayashankar \& Sridaran, 2016; Volkert, 2018). The visualisation of the written interview data can help researchers enhance clarity between data and findings (Dickinson, 2010) and provide readers with visual displays to synthesise the big ideas from text analysis, such as tables or bar charts shown in quantitative data analysis (Ramlo, 2011). Focusing on students' concrete answers, I eliminated punctuation and common stop words such as "we", "and", "the" and "there" in word clouds to generate a meaningful visual representation allowing key information analysis on answering the research question.

\section{Results}

This study explored the effectiveness of applying smartphone-based collaborative vlog projects on EFL students' speaking performance and learning engagement in China. The results are presented following the research questions. I first compared the mean scores of the speaking pretest and post-test to answer RQ1.

\section{RQ1: Are there any significant differences between the pretest and post-test speaking test results?}

To answer this question, a paired-sample $t$ test was applied to calculate any statistically significant differences in the mean scores of students' speaking pretest and post-test scores. Before conducting the test, I examined the collected data of the pretest and post-test scores to check whether they demonstrated a normality distribution. The purpose of testing normality distribution was to correctly calculate the significance level ( $p$ value < .05) through comparing mean value (Ghasemi \& Zahediasl, 2012; Mishra et al., 2019). The result of normality distribution is presented in Figure 4.

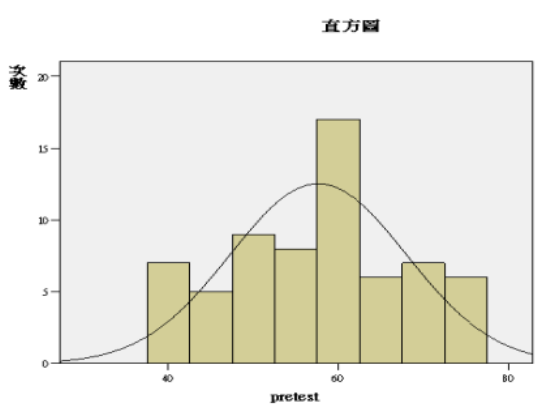

(a) pretest
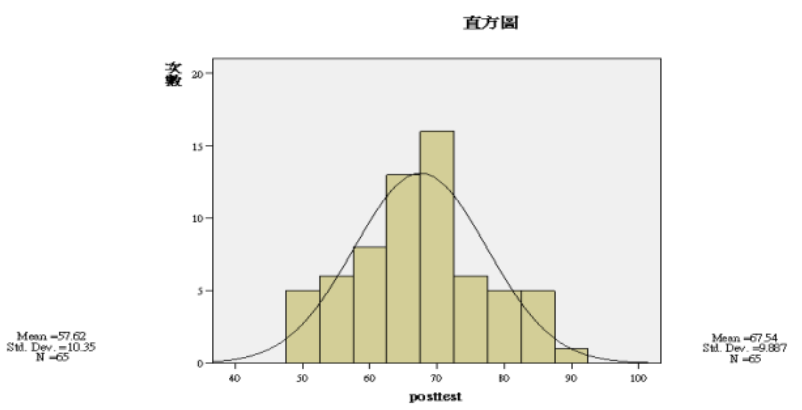

(b) post-test

Figure 4. Normality distribution of pretest and post-test speaking scores

After obtaining a normality distribution of the pretest and post-test scores, I conducted the paired-sample $t$ test to compare the mean scores of the pretest and post-test speaking scores. Table 1 shows the results of the paired-sample $t$ test for mean scores of the speaking tests. 
Table 1

Paired t test results (differences between pretest and post-test)

\begin{tabular}{llllccl}
\hline Test & N & Mean & SD & T value & Sig. (2-tailed) & $\begin{array}{l}\text { Effect size } \\
(\text { Cohen's } \boldsymbol{d} \text { ) }\end{array}$ \\
\hline Pretest & 65 & 57.62 & 10.35 & 29.38 & $<.001$ & 1.46 \\
\hline Post-test & 65 & 67.54 & 9.89 & & & \\
\hline
\end{tabular}

Table 1 shows that students' speaking performance improved from a pretest mean score 57.62 to a posttest mean score 67.54. This result was statistically significant $(t=29.38, p<.001)$ and indicated that students' speaking performance had greater gains in the post-test than in the pretest. It shows that students' speaking abilities significantly improved in speaking quality after the intervention of the smartphone-based collaborative vlog projects. Finally, I examined the effect size and obtained the value of the Cohen's $d=$ 1.46, indicating an extremely large effect (Cohen, 1988).

\section{RQ2: What are students' perceptions of group collaboration in the smartphone-based collaborative vlog projects?}

Among the 65 returned questionnaires, 62 were valid after rejecting the invalid (i.e., not entirely completed) responses. The resultant response rate was $95.38 \%$. Before computing the descriptive analysis, I reversed the scoring of the negative items first and then applied Cronbach's alpha in SPSS to calculate the reliability of the group collaboration questionnaire first. The results indicate that the questionnaire was reasonably reliable $(a=0.860)$.

The data from the questionnaire regarding the students' perceptions of applying group collaboration in vlog projects were analysed to answer RQ2. Table 2 presents the descriptive results of the students' responses to group collaboration in the vlog projects. From the 62 returned questionnaires, I computed the collected the data in SPSS. The mean scores of the seven questions ranged from 3.03 to 4.10, indicating that the students experienced moderately high levels of agreement and positive feedback on group collaboration. These results indicate that students had a positive attitude and enjoyed the process of filming videos. Screenshots of the vlog project are presented in Figure 5.

Table 2

Descriptive statistics of the perceptions of group collaboration

\begin{tabular}{clcc}
\hline No. & \multicolumn{1}{c}{ Statement } & Mean & SD \\
\hline 1. & $\begin{array}{l}\text { I enjoyed learning English through collaborating with others on vlog projects } \\
\text { 2. }\end{array}$ & 3.65 & .993 \\
& $\begin{array}{l}\text { I enjoyed collaborating with my teammates on collaborative vlog projects we } \\
\text { did this semester. }\end{array}$ & 3.79 & .960 \\
3. & $\begin{array}{l}\text { I felt that I learned more about videotaping and editing skills from peer } \\
\text { collaborating than working alone. }\end{array}$ & 3.03 & .905 \\
4. & $\begin{array}{l}\text { Doing collaborative vlog projects was not a waste of time. } \\
\text { 5. }\end{array} \quad \begin{array}{l}\text { My English expression improved through doing collaborative vlog projects } \\
\text { with my teammates. }\end{array}$ & 3.90 & .783 \\
6. & I enhanced my ability to edit videos through filming collaborative vlogs. & 3.92 & .685 \\
7. I gained more confidence in English speaking after doing collaborative vlog & 3.76 & .740 \\
\hline & & & \\
\hline
\end{tabular}

Note. $N=62$

Table 2 presents the results of descriptive statistics for the average scale for the questionnaire regarding group collaboration. The mean value of the 7 -item questionnaire of group collaboration is 3.74 , indicating that students experienced a slightly high level of group collaboration in this study. The results revealed that the students enjoyed the two vlog projects and thought it was a beneficial use of their time $(\mathrm{Q} 4: M=4.10)$. The second highest rating indicated that the projects increased their video editing skills (Q6: $M=3.92$ ), followed by improving their English (Q5: $M=3.90)$. The students also strongly indicated that they enjoyed collaborating on the project $(\mathrm{Q} 2: M=3.79)$, increased their confidence in speaking English $(\mathrm{Q} 7: M=3.76)$, and enjoyed learning through collaboration $(\mathrm{Q} 1: M=3.65)$. The results of $\mathrm{Q} 3$ were predominantly neutral (39\%), 27\% indicated that they learned more in working alone, and 34\% felt that they learned more videotaping and editing skills through peer collaboration. 
Overall, the students enjoyed the collaborative vlog projects. They appreciated using technology and having collaborative learning experiences, which resulted in increased confidence in enhancing their English speaking skills. Results overwhelmingly suggest that the collaborative vlog projects used in this study help students experience the benefits of group collaboration.
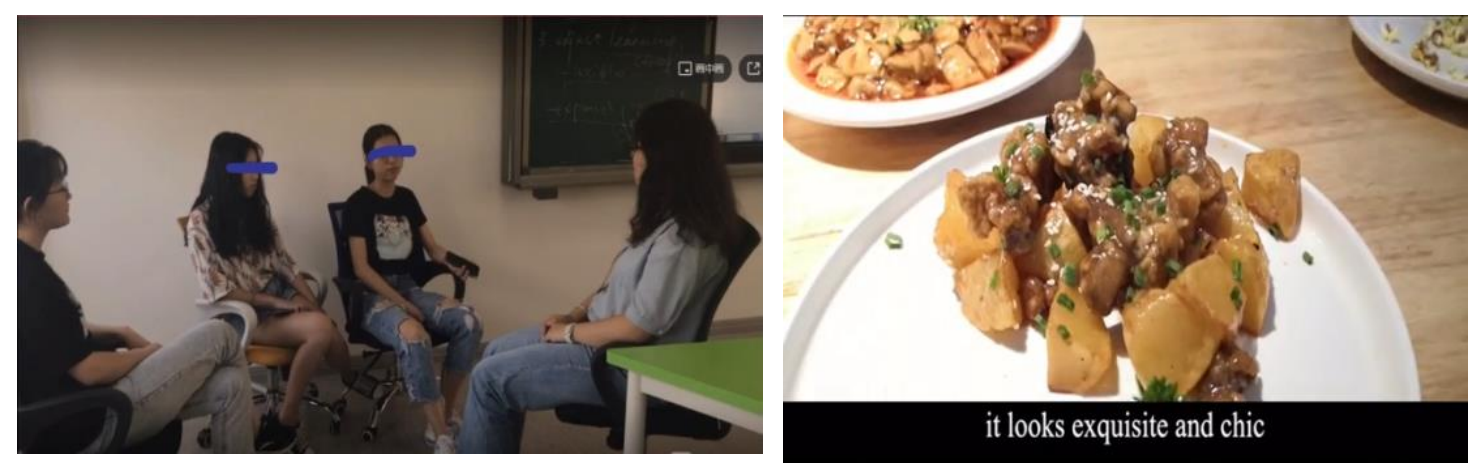

Figure 5. Screenshots of vlog projects

\section{RQ3: How do the students perceive the learning experiences of smartphone-based collaborative vlog projects in their final reflections?}

The students' learning experiences were collected through the 65 final reflection papers, stating their thoughts and opinions about the vlog projects. Table 3 presents the themes and some samples of the students' responses. The reflections showed a remarkable positive perception, with $100 \%$ of the students $(65 / 65)$ commenting on their enjoyment in the project-based tasks.

Students' answers were divided into three categories: digital media production skills, communication in teamwork and multiple proficiencies. The data in the first category show that the students appreciated the opportunities to learn how to edit videos and develop multimedia production skills. All the processes of vlog making, from the initial step group scriptwriting, on-site vlog shooting, to final step post-editing vlogs, enabled students to use various digital tools on the smartphones. The students appreciated the introduction of vlog projects in the EFL classroom since their confidence in English speaking increased and they acquired video editing skills simultaneously. This equips them with the soft skills (i.e., teamwork, problemsolving, organisation, negotiation and creativity) needed in the future workforce. Even though most of them had no prior experience with making vlogs on smartphones, they were motivated to develop smartphonebased digital media literacy - an important hands-on skill in a ubiquitous collaborative learning environment with linking hands-on educational pedagogy.

The second category was communication in teamwork. Several students agreed that working in teams helped them experience the joy of group collaboration and cultivate their responsibility to reach the common goals of the tasks. Approximately $90 \%$ of the participants (59/65) wrote that they perceived that their communication skills, including problem-solving and the exchange of ideas, improved during the process of the two vlog projects, as they were involved in both process-oriented and product-oriented activities. It is important to create positive dialogue and foster group cohesion (i.e., demonstrating mutual commitment to the task) in teamwork. Hence, good communication skills in building team dynamics can help group members recognise each other's strengths, leading to more engagement and successful outcomes towards the team goals.

The third category was demonstrating multiple proficiencies. The students agreed that they enjoyed speaking with confidence during the vlog projects. They expressed interest in engaging in meaningful learning in a real-world context, which provides them with the opportunity to apply theory to practice. Multiple proficiencies include both professional and non-professional abilities. The students not only applied what they learned in classes in the vlog projects but also learned other skills, such as organisation and time management. These soft skills are important for entering future workplaces. 
Table 3

Classified themes from student written reflections about the vlog projects

\section{A. Digital media production skills}

$\checkmark \quad$ I thought that all-round exercises not only boosted our English level but also enhanced our computer skills, along with increasing our hands-on abilities.

$\checkmark \quad$ I learned how to record PowerPoint videos using WPS Office.

$\checkmark \quad$ I also learned how to edit videos from my partner. It was an extra benefit for me.

$\checkmark \quad$ After finishing these two vlogs, we learned how to edit video clips using editing apps on smartphones.

$\checkmark \quad$ Even though I did not know how to edit the first video we filmed, my group member taught me how to solve it, which was helpful in developing my multimedia production skills.

\section{B. Communication in teamwork}

\begin{tabular}{|c|c|}
\hline$\checkmark$ & $\begin{array}{l}\text { I enjoyed making two group vlog assignments the most because we could learn something from } \\
\text { effective distribution of tasks. }\end{array}$ \\
\hline$\checkmark$ & $\begin{array}{l}\text { From the two projects, I learned not only how to use smartphones to produce vlogs for the first } \\
\text { time but also learned the importance of teamwork. }\end{array}$ \\
\hline$\checkmark$ & $\begin{array}{l}\text { Getting along with my partners, I found it happy, comfortable and meaningful to do vlog } \\
\text { projects. }\end{array}$ \\
\hline$\checkmark$ & $\begin{array}{l}\text { Through filming the two vlogs, I learned how to cooperate with my partner in a group and } \\
\text { understand others' thoughts. }\end{array}$ \\
\hline$\checkmark$ & $\begin{array}{l}\text { I appreciated making group vlogs, especially the first one. When we created the first vlog, we } \\
\text { had a long discussion and organised the vlog content before filming. }\end{array}$ \\
\hline \multicolumn{2}{|r|}{ C. Multiple proficiencies } \\
\hline$\checkmark$ & I felt more confident about sharing my ideas in English with $n$ \\
\hline$\checkmark$ & $\begin{array}{l}\text { I thought it was a very good opportunity for us to practise not only our oral English but also our } \\
\text { organisational capabilities. }\end{array}$ \\
\hline$\checkmark$ & We could speak English outdoors more bravely, and it also improved our speaking skills. \\
\hline$\checkmark$ & I learned how to get organised and have effective time management for completing assignments. \\
\hline$\checkmark$ & $\begin{array}{l}\text { It helped us to put our understanding of the texts into practice and express it. I thought the topics } \\
\text { of the vlogs were very meaningful. }\end{array}$ \\
\hline
\end{tabular}

\section{RQ4: According to students' interviews, what are the opportunities and challenges in the process of smartphone-based collaborative vlog projects in English learning?}

The six interviewees were positive about the potential for student-filmed vlogs to help EFL learners improve speaking performance and learning experiences. They appreciated that the implementation of vlog projects in English classes helped them improve collaboration skills with peers, enhance oral communication skills in the target language, and develop effective organisational skills in extracting important vlog materials in the final products. Their speaking proficiency and fluency were improved after they engaged in informal learning contexts, away from the walls of the classroom, using smartphones to learn new knowledge. However, the interviewees raised a few challenges. They spent too much time on video-editing and experienced difficulties in choosing proper video content, in particular post-editing procedures and vlog content selection to be presented in the final products. They also gave suggestions for improving future course design.

The main responses are displayed visually to present their inner thoughts and in-depth perspectives on the vlog project activities. The word cloud results of opportunities and challenges, based on the interview transcripts, are shown in Figure 6. Larger words indicate more frequent word usage. 


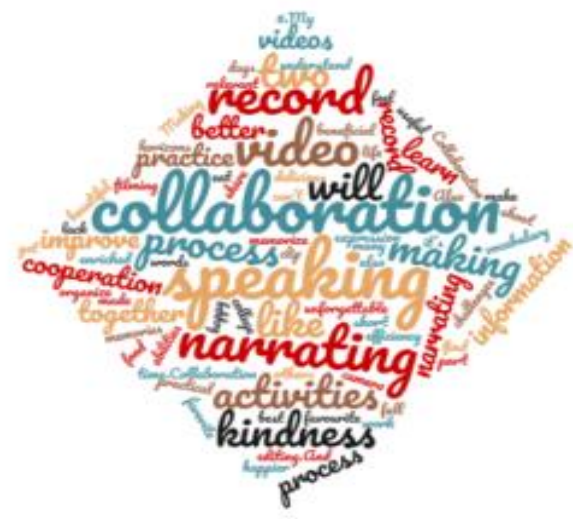

(a) Opportunities

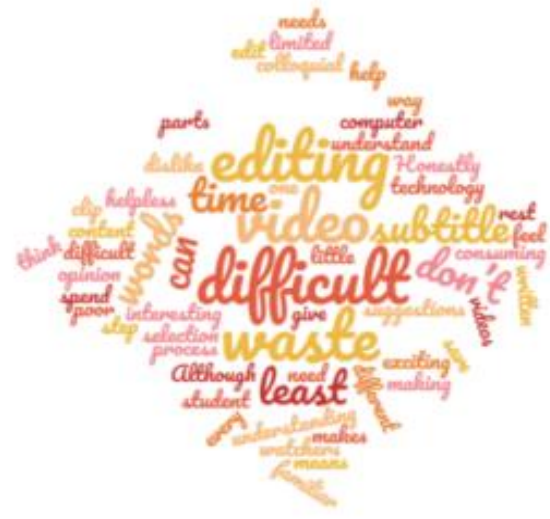

(b) Challenges

Figure 6. Word cloud results of student responses to interview questions

\section{Results of students' three interview questions}

What do you think of the opportunities you experienced from the vlog projects in English learning? The interview results show that the six interviewees commented positively on the vlog projects in English learning. They understood the course design based on the social constructivism theory, which encouraged them to experience active learning and meaningful learning occurred in real-life contexts. All the students agreed that the vlog projects were beneficial for them in facilitating more participation and engagement in English learning, along with being capable to solve any issues in producing videos. After conducting an analysis of the word clouds, I found that "collaboration", "speaking" and "narrating" were the three biggest words shown in the visual image (see Figure 6a). All the interviewees shared similar thoughts about the opportunities of the vlog projects, stating that filming vlogs provided them with the opportunity to improve collaboration skills with peers. To protect the students' anonymity, their names are indicated by letters. Below are example responses to this interview question from students $\mathrm{C}, \mathrm{D}$ and $\mathrm{F}$ :

I enjoyed working with others under a fair distribution of work. In a group of four students, all of us came up different ideas about the vlog content. After discussing, we decided which idea was the best. We had good social interaction and group collaboration. (Student C)

I am glad to have this opportunity to do collaboration with my team members. After the group leader assigned the work distribution, everyone started doing his/her job in order to complete the tasks on time. (Student D)

All members actively engaged in vlog making because we could learn new knowledge through collaboration. The process of collaboration with others was friendly, and we had a lot of fun in teamwork. (Student F)

The second biggest word in the word cloud is "speaking". Five interviewees added that they became confident to speak English outside of classrooms. They believed that the vlog project had a positive impact on their English speaking. They agreed that speaking abilities can be improved by participating in the vlog tasks because the implementation of vlog projects was useful for practising English speaking. The following excerpts support this statement:

We needed to practise speaking before shooting the videos in order to produce high-quality vlogs for the audience watching. The process of practising English speaking definitely enhanced our speaking fluency and accuracy. (Student B)

I enjoyed the class very much because English speaking was my favorite part in which I could use the target language to express my thoughts in the vlog projects. I am not afraid to talk to others in English anymore. (Student E) 
Finally, students found that the vlogs were useful in their language learning acquisition. While narrating (making a voice-over), they needed to effectively organise the important and necessary content presented in the vlogs, along with practising their English speaking. They also expressed a sense of achievement from making the voice-over. Two interviewees' response excerpts are provided below:

The part I like the most was giving a description for the vlogs we filmed. I could organise the content before narrating, rather than merely following the textbook content. I was happy that I can decide what I want to say. (Student A)

My group member and I had a sense of achievement while narrating the vlogs, which made us go back to the situation we filmed videos and we produced a BABY [a finished vlog] collaboratively. (Student F)

Overall, the responses obtained from the focus group interview supported and validated the survey findings. All the results indicate that the students experienced an enriched learning environment in terms of language acquisition.

What do you think of the challenges you observed from the vlog projects in English learning?

Difficulty and editing were the two biggest words shown in the word clouds image (see Figure 6b). The result show that the interviewees found choosing appropriate vlog content difficult. In addition, the process of editing videos was very time-consuming for mixing various video inputs and creating transitions to the video clips. They identified that these challenges were tiring and troublesome. This is demonstrated in the following excerpts:

The process of post-editing regarding cutting and trimming the video, adding music background and subtitles, etc. is very difficult for us. Although we enjoyed making voiceover for the vlogs, we had pressure to complete the tasks under time restraints for submitting vlogs. (Student B)

We filmed many interesting vlog materials and it was difficult for us to decide which were suitable or not to fit the 3-minute vlog project. (Student D)

To ensure the high quality of vlog products, we also spent tons of time deciding what elements can make vlogs better during the editing process. If things were going wrong, we needed to fix them immediately. (Student E)

What's your suggestion for improving the vlog project?

Students' answers to this question were classified into three categories: shooting more vlogs about Chinese cultures; assigning a group leader; integrating a question-and-answer (Q\&A) session. Three students suggested that teachers should assign students to shoot videos introducing Chinese culture and upload them to social media, so that more foreigners can view vlogs made by Chinese students. Moreover, two students suggested that it would be better if they had a group leader to deal with all the unexpected situations. Finally, one student mentioned that she would prefer adding a Q\&A session in the vlog in order to create more interaction with viewers. Excerpts of responses to this question are given below:

If we can integrate Chinese cultures in vlog projects, such as paper making, Chinese painting, etc., it will be fantastic to promote cultures connection with people from all over the world. (Student A)

I suggest that teachers can assign a group leader who is responsible for organising things in an effective way. It can save our time to implement the tasks. (Student C)

If we add a Q\&A session in the vlogs, the audience can respond to our questions. It is great to increase interaction with the viewers. (Student F) 


\section{Discussion}

The purpose of this study was to explore EFL students' speaking performance and learning engagement in implementing smartphone-based collaborative vlog projects in a tertiary-level EFL class in China. Several major findings were found. First, students' post-test speaking scores were significantly higher than the pretest speaking scores $(t=29.38, p<.001)$. The speaking pretest revealed that the mean score on the TOEFL iBT independent speaking test was lower than 60/100. It indicates that the majority of the participants' fluency (pacing and pausing in speech) and pronunciation (the accuracy of correct pronunciation and intonation) were not satisfied. Their pretest responses lacked fluid expression, demonstrated limited vocabulary range and correctness of the whole sentences, and some development of ideas was rigid. Limited relevant content expression and problems with fluency and coherence were also found. Conversely, the mean score of the speaking post-test was 67.54/100, a remarkable increase in comparison with the pretest scores. These results indicate that integrating student-created video projects can enhance students' speaking proficiency; the students also made obvious progress and achievement in speaking tests. One of the reasons for the progress is attributed to students working together to discuss how to correctly express their ideas in English and find solutions after group collaboration. Students also stated that their communicative abilities in English improved because they could apply the target language in a real-life setting.

The results are consistent with Vygotsky's (1986) social constructivism theory, indicating that knowledge construction was built upon engaging social interaction, sharing opinions, and helping each other. The findings are also in line with those in previous studies (Lai et al., 2016; Morris, 2011; Schultz \& Quinn, 2013) on the effects of social interaction in learning, which identified that learners tend to benefit from collaborating in groups, rather than working alone. The findings also show that the development of the students' ZPD took place through social interaction and learning occurred via their more capable peers' scaffolding and support, as hypothesised by Vygotsky (1978). They advanced their ZPD and enhanced their cognitive processes (Chaiklin, 2003). The vlog projects provided students with opportunities to activate their verbal and visual learning channels to construct new knowledge.

Gromik $(2012,2015)$ reported that hand-held mobile devices can be learning tools for students to express their knowledge via recording and creating videos. Students' roles shift from passive learners in the classroom to active producers of learning contexts (Schultz \& Quinn, 2013). Hence, the study findings illustrate the perceived learning in an immersive technology-supported collaborative learning environment, leading to cognitive development through engaging in vlog projects.

Students improved their speaking performance because the collaborative vlog projects provided them with the opportunities to experience the dynamics of group interaction in terms of the organisation and discussions of vlog content with peers. Through working together, they created social interactions in English learning and experienced peer feedback when they found any mistakes in the vlog projects. Such peer instruction activities facilitate cognitive outcomes and motivate students to complete higher-quality group tasks. This could be explained by students' active engagement and positive learning experiences during the process of collaborative vlog projects. These results are consistent with those in other video projects in English learning (Anas, 2019; Perry, 2018; Yang \& Wu, 2012) which indicated the positive feedback of implementing video projects in educational contexts.

There is also evidence of students' positive learning attitude, including taking an active role in English learning and staying focused on producing the vlog projects. These findings support Chapelle's (2001) six criteria: language-learning potential, learner fit, meaning focus, authenticity, positive impact and practicality. The students recognised the connection between the course assignments and real-world situations to create authentic learning. As such, students had more enthusiasm to be involved and showed active learning in the vlog projects in EFL learning (Aldukhayel, 2019; Anas, 2019; Hung, 2011; Perry, 2018). Students became more conscious of their speaking performance and felt confident expressing their ideas in English in the vlog tasks to connect learning content and authentic contexts - a meaningful medium for them to learn the target language (Encalada \& Sarmiento, 2019; Hung, 2011). Hence, their positive affective factors, such as enthusiasm and engagement, were high, and they created a sense of belonging and cohesion in group work. 
Having learner autonomy, playing an active role in learning and engaging in social interaction became the central part of the collaborative vlog projects. These results are similar to the conclusions of Morris (2011) and Lai et al., (2016), who reported that working in teams was helpful for students to exhibit their creativity with group members, gain a deeper understanding in learning material, and become autonomous learners. Overall, students tended to enjoy producing collaborative vlogs in a technology-enhance learning setting with their peers. Through participating in content-related vlog projects, students realised the connections and relationship between what they were learning in the classroom and the real world. They produced videos relevant to the learning materials and developed content creation skills. These results, indeed, echoed Bloom's digital taxonomy (Churches, 2008), reaching analysing, evaluating, and creating levels; students experienced a sense of achievement in learning. One of the reasons for students' positive feedback is most likely that students may feel more comfortable expressing their innovative thinking with peers and developing higher-order thinking skills after implementing the collaborative vlog projects than in a conventional classroom setting.

Students' final reflections evidence the theme of the digital media production skills. Students possessing digital media production skills will have more opportunities to meet the needs of the 21 st century job market. When students were producing vlog projects, they not only acquired language content but also learned media production skills. These enriching observations are in line with those of previous studies stating the importance of the 21st century skills in English learning (Anas, 2019; Niemi \& Multisilta, 2016; Perry, 2018). The results of this study indicate that the use of collaborative vlog project tasks can facilitate students' positive learning experiences, including developing their digital media production skills, enhancing their communication strategies, and demonstrating their multiple competencies: problemsolving and creativity (P21, 2019; Scott, 2015; Yang \& Wu, 2012). The digital media production skills, communication strategies, problem-solving and creative abilities from the vlog projects all combined to prepare students with 21st century skills and become successful learners (Perry, 2018; Scott, 2015; Sousa, 2017; Trilling \& Fadel, 2009; Yang \& Wu, 2012). These skills will be beneficial in helping them solve the real-world problems in the future.

Students shared their observations of the opportunities of the two vlog projects. The integration of vlog projects was effective in fostering their learning engagement, facilitating a spirit of collaboration and learning through lively activities. The results are consistent with those in studies on video projects in English classrooms (Anas, 2019; Yang \& Wu, 2012), indicating positive feedback for implementing video projects in an English class. This was evident in students' interview responses and positive learning experiences during the process of producing vlog projects. However, they considered the difficulty of selecting filmed video content and the time consumed on post-editing as challenges. The findings are similar to those of H. C. Huang (2015). Huang suggested that students with better multimedia editing skills could be assigned amongst different groups in order to decrease students' workload on post-editing. As for the students' suggestions, English teachers who are interested in integrating vlog projects in EFL classrooms may consider the two challenges raised by the interviewees - the choice of vlog content and time needed for post-production.

Finally, the process of technology-supported learning signifies the fact that students enjoy the instant gratification provided by smartphones in vlog productions. Students could view the footage on their smartphones. This is the concept of "what you see is what you shoot" - instant satisfaction from fast-food culture. The instant gratification (immediate satisfaction) is important for young generations to experience pleasure without delay because they are accustomed to living with high-speed tools (Teo, 2013). This may bring students to actively engage in learning and have a desire to improve their speaking performance on the vlog projects. This could be one of the reasons why the students enjoyed participating in the two vlog projects: they could watch their self-produced vlogs without waiting and experience a sense of achievement.

\section{Pedagogical implications}

This study reveals several pedagogical implications for EFL educators. First, integrating collaborative vlog projects into the course syllabus develops students' creative skills and digital media production skills. If EFL teachers are willing to embrace innovative teaching strategies, it is ideal to design collaborative vlog projects across different cultures to increase students' better understanding and appreciation of cultural diversity as well as improving language skills simultaneously. Moreover, a technology-integrated teaching and learning environment can provide students with emotional and academic support to increase learning 
engagement with creative and problem-solving skills, which are important for their future workplaces. Through student-focused, careful course design, EFL learners' language proficiency and higher-order thinking skills can be stimulated and enhanced. As a result, they become active learners who are better prepared for the needs of the changing world.

Second, the teaching strategies of designing social constructivism and technology integration in this study demonstrate the effectiveness of collaborative vlog projects in English learning. Students in this study went through different phases of discussing, video making, and post-editing, a transformative learning pedagogy by integrating technology-supported projects in a socially interactive setting. In essence, I was not the controller or dominator in the classroom. On the contrary, I provided students with scaffolding to help them master the various tasks to complete the project. Students, therefore, could take responsibility for their own learning, and autonomy was the result. The cycles of teaching and learning were in line with social constructivism theory. Hence, incorporating smartphone-based collaborative vlog projects in language learning could contribute to a positive learning environment.

Finally, it is important for teachers to understand students' learning characteristics. The digital native generation (Prensky, 2001) uses smartphones every day, and the mobile devices are used for entertainment. A great many students, unfortunately, do not understand the concept of using smartphones as language learning devices. EFL educators may offer learning strategies to students and help them increase their awareness of the potential of using smartphones for language learning because they are already natural users of these technologies. Based on the characteristics of digital natives (i.e., they are surrounded by new technologies and remain plugged into smartphones every day), EFL teachers should design creative learning activities to help them engage in meaningful and authentic learning, connecting to real-life situations.

As the findings of this study show, students were inspired by the vlog projects because they thought that the hands-on tasks were fun, a key success factor for leading to deeper engagement in learning. Young learners at tertiary education are comfortable with using digital devices and embracing a digital-first approach to life and learning. This will allow students to develop their digital media production skills for equipping themselves for the future workforce.

\section{Conclusion}

The results of this study indicate that, after the 10-week smartphone-based collaborative vlog projects, the EFL college students demonstrated significant improvement in English speaking proficiency, enjoyed dynamic group collaboration atmosphere, and developed 21 st century skills, such as digital media production and communication. Furthermore, qualitative responses from the focus group interviews indicate that applying collaborative vlog projects in English learning could foster learning engagement and stimulate higher-order thinking skills shown in the revised Bloom's taxonomy (Anderson et al., 2001). Students experienced authentic practice to present their thoughts and creativity in English in real-life contexts. Specifically, they viewed vlog-filming projects as a useful learning activity for evaluating their learning process and products, which are usually unseen in traditional EFL classrooms. They had greater control over their handheld devices and benefited from using their smartphones to create meaningful learning tasks in group collaboration. The findings align with social constructivism - knowledge construction is based on the process of learners' interaction with others by sharing views and their active engagement in learning. Finally, students could see the possibilities of smartphones as potential learning tools in English learning.

Although this study successfully applied smartphone-based collaborative vlog projects in an EFL classroom, certain limitations should be considered. First, the sample size in this study was limited to 65 sophomore students in China; therefore, the findings may not yield generalisability. Recruiting more participants in a long-term experimental period could enhance the generalisability of the results. Second, the study did not investigate students' affective factors and their perceptions of technology acceptance in learning. Future studies could examine other variables, such as different academic majors and individual affective factors, to obtain an overall understanding of other factors affecting EFL learners' behaviours and attitude in accepting technology-enhanced language learning, along with learning outcomes. Finally, the study did not focus on students' writing proficiency. The two output skills, writing and speaking, in EFL learning can be evaluated by smartphone integration in learning when students write vlog scripts. By doing 
so, students can learn how to generate and discuss ideas, and revise video scripts in order to improve the writing quality. Future studies could apply vlog projects in combining four language-skills in EFL classrooms in order to promote students' global language proficiency.

The literature on filming digital videos and the findings of this study have shown that smartphone-based video-making can be an effective language learning tool in mobile-assisted language learning contexts due to the increasing ubiquity of technology. The results show that students were more engaged in learning activities than in traditional classrooms because using technology increases their engagement and makes learning goals achievable in an effective fashion. The features of smartphone-based learning in education - audio, video and photos - create visual learning and increase students' learning interests. The content built for smartphone-based learning is dynamic and active for students' learning processes and outcomes. Students experience using cutting-edge teaching methods and feel empowered by their achievements in learning - all thanks to smartphone-based learning.

\section{Acknowledgements}

The author is grateful to Daniel Dusza, a lecturer at Kanda Institute of Foreign Languages, Japan for proofreading the manuscript. A part of this paper was presented at the 4th International Conference on EEducation, E-Business and E-Technology in 2020. This work was supported by a Fujian University of Technology Start-up Research Grant (No. E21100099).

\section{References}

Aldukhayel, D. (2019). Vlogs in L2 listening: EFL learners' and teachers' perceptions. Computer Assisted Language Learning. https://doi.org/10.1080/09588221.2019.1658608

Anas, I. (2019). Behind the scene: Student-created videos as a meaning-making process to promote student active learning. Teaching English with Technology, 19(4), 37-56. https://www.tewtjournal.org/issues/volume-2019/volume-19-issue-4/

Anderson, L. W., Krathwohl, D. R., \& Bloom, B. S. (2001). A taxonomy for learning, teaching, and assessing: A revision of Bloom's taxonomy of educational objectives (Complete ed.). Longman.

Battelle for Kids. (2019). Framework for 21st century learning. http://static.battelleforkids.org/documents/p21/P21_Framework_Brief.pdf

Baumgartner, H., \& Steenkamp, J.-B. E. M. (2001). Response styles in marketing research: A crossnational investigation. Journal of Marketing Research, 38(2), 143-156. https://doi.org/10.1509/jmkr.38.2.143.18840

Bletzer, K. V. (2015). Visualizing the qualitative: Making sense of written comments from an evaluative satisfaction survey. Journal of Educational Evaluation for Health Professions, 12(12). https://doi.org/10.3352/jeehp.2015.12.12

Braun, V., \& Clarke, V. (2006). Using thematic analysis in psychology. Qualitative Research in Psychology, 3(2), 77-101. https://doi.org/10.1191/1478088706qp063oa

Chaiklin, S. (2003). The zone of proximal development in Vygotsky's analysis of learning and instruction. In A. Kozulin, B. Gindis, V. Ageyev, \& S. Miller (Eds.), Vygotsky's educational theory in cultural context (pp. 39-64). Cambridge University Press. https://doi.org/10.1017/CBO9780511840975.004

Chapelle, C. A. (2001). Computer applications in second language acquisition: Foundations for teaching, testing and research. Cambridge University Press. https://doi.org/10.1017/CBO9781139524681

Churches, A. (2008). Bloom's digital taxonomy. https://www.academia.edu/30868755/Andrew_Churches_Blooms_Digital_Taxonomy_pdf

Cohen, J. (1988). Statistical power analysis for the behavioral sciences. Academic Press, Inc.

Council of Europe. (2001). Common European framework of references for languages: Learning, teaching, assessment. Cambridge University Press. https://rm.coe.int/16802fc1bf

DePaolo, C. A., \& Wilkinson, K. (2014). Get your head into the clouds: Using word clouds for analyzing qualitative assessment data. Tech Trends, 58(3), 38-44. https://doi.org/10.1007/s11528-014-0750-9

Dickinson, W. B. (2010). Visual displays for mixed methods findings. In A. Tashakkori \& C. Teddlie (Eds.), Handbook of mixed methods in social \& behavioral research (2nd ed., pp. 469-504). SAGE Publications. https://doi.org/10.4135/9781506335193.n19 
Educational Testing Service. (n.d.). TOEFL iBT® speaking section. https://www.ets.org/toefl/testtakers/ibt/about/content/speaking

Educational Testing Service. (2019). TOEFL iBT® Test: Independent speaking rubrics. https://www.ets.org/s/toefl/pdf/toefl_speaking_rubrics.pdf

Encalada, M. A. R., \& Sarmiento, S. M. A. (2019). Perceptions about self-recording videos to develop EFL speaking skills in two Ecuadorian universities. Journal of Language Teaching and Research, 10(1), 60-67. https://doi.org/10.17507/jltr.1001.07

Ghasemi, A., \& Zahediasl, S. (2012). Normality tests for statistical analysis: A guide for non-statisticians. International Journal of Endocrinology Metabolism, 10(2), 486-489. https://doi.org/10.5812/ijem.3505

Glanz, K., Rimer, B. K., \& Viswanath, K. (2008). Theory, research, and practice in health behavior and health education. In K. Glanz, B. Rimer, \& K. Viswanath (Eds.), Health behavior and health education (pp. 23-40). Jossey-Bass.

Gromik, N. A. (2012). Cell phone video recording feature as a language learning tool: A case study. Computers \& Education, 58, 223-230. https://doi.org/10.1016/j.compedu.2011.06.013

Gromik, N. A. (2015). The effect of smartphone video camera as a tool to create digital stories for English learning purposes. Journal of education and Learning, 4(4), 64-79. https://doi.org/10.5539/jel.v4n4p64

Huang, H. C. (2015). The effects of video projects on EFL learners' language earning and motivation: An evaluative study. International Journal of Computer-Assisted Language Learning and Teaching, 5(1), 53-70. https://doi.org/ 10.4018/IJCALLT.2015010104

Huang, H. W., Lin, Q., \& Darragh, J. J. (2020). Understanding EFL learners' self-efficacy of collaborative translation in a blended English course. In Proceedings of the 4th International Conference on E-education, E-business, and E-technology (pp. 78-83). Association for Computing Machinery. https://doi.org/10.1145/3404649.3404661

Huang, H. W., Wu, C.-W., \& Chen, N.-S. (2012). The effectiveness of using procedural scaffoldings in a paper-plus-smartphone collaborative learning context. Computers \& Education, 59(2), 250-259. https://doi.org/10.1016/j.compedu.2012.01.015

Hung, S.-T. (2011). Pedagogical applications of vlogs: An investigation into ESP learners' perceptions. British Journal of Educational Technology, 42(5), 736-746. https://doi.org/10.1111/j.14678535.2010.01086.x

Jayashankar, S., \& Sridaran, R. (2016). Superlative model using word cloud for short answers evaluation in eLearning. Education and Information Technologies, 22, 2383-2402. https://doi.org/10.1007/s10639-016-9547-0

Kilickaya, F. (2006). 'Text-to-speech technology': What does it offer to foreign language learners? CALL-EJ Online, 7(2). http://callej.org/journal/7-2/Kilickaya.html

Kim, H., \& Kwon, Y. (2012). Exploring smartphone applications for effective mobile-assisted language learning. Multimedia-Assisted Language Learning, 15(1), 31-57. https://doi.org/10.15702/mall.2012.15.1.31

Kirkgöz, Y. (2011). A blended learning study on implementing video recorded speaking tasks in taskbased classroom instruction. TOJET: The Turkish Online Journal of Educational Technology, 10(4), 1-13. http://www.tojet.net/articles/v10i4/1041.pdf

Lai, C., Lei, C. L., \& Liu, Y. (2016). The nature of collaboration and perceived learning in wiki-based collaborative writing. Australasian Journal of Educational Technology, 32(3), 80-95. https://doi.org/10.14742/ajet.2586

Larson, L. C., \& Miller, T. N. (2011). 21st century skills: Prepare students for the future. Kappa Delta Pi Record, 47(3), 121-123. https://doi.org/10.1080/00228958.2011.10516575

McConnell-Henry, T., James, A., Chapman, Y., \& Francis, K. (2010). Researching with people you know: Issues in interviewing. Contemporary Nurse, 34(1), 2-9. https://doi.org/10.5172/conu.2009.34.1.002

McKenney, S., \& Voogt, J. (2011). Facilitating digital video production in the language arts curriculum. Australasian Journal of Educational Technology, 27(4), 709-726. https://doi.org/10.14742/ajet.946

Meyer, E., \& Forester, L. (2015). Implementing student-produced video projects in language courses: Guidelines and lessons learned. Die Unterrichtspraxis/Teaching German, 48(2), 192-210. https://doi.org/10.1111/tger.10195

Mishra, P., Pandey, C. M., Singh, U., Gupta, A., Sahu, C., \& Keshri, A. (2019). Descriptive statistics and normality tests for statistical data. Annals of Cardiac Anaesthesia, 22(1), 67-72.

https://doi.org/10.4103/aca.ACA_157_18 
Morris, C. (2011). Social constructivism and tourism education. Journal of Hospitality, Leisure, Sport and Tourism Education, 10(2), 103-108. https://doi.org/10.3794/johlste.102.385

Mulligan, C., \& Garofalo, R. (2011). A collaboration writing approach: Methodology and student assessment. The Language Teacher, 35(3), 5-10. https://jalt-publications.org/files/pdfarticle/art1_13.pdf

Nami, F. (2020). Educational smartphone apps for language learning in higher education: Students' choices and perceptions. Australasian Journal of Educational Technology, 36(4), 82-95. https://doi.org/10.14742/ajet.5350

Niemi, H., \& Multisilta, J. (2016). Digital storytelling promoting twenty-first century skills and student engagement. Technology, Pedagogy and Education, 25(4), 451-468. https://doi.org/10.1080/1475939X.2015.1074610

Nussbaum, M., Alvarez, C., McFarlane, A., Gomez, F., Claro, S., \& Radovic, D. (2009). Technology as small group face-to-face collaborative scaffolding. Computers \& Education, 52(1), 147-153. https://doi.org/10.1016/j.compedu.2008.07.005

Nyumba, T. O., Wilson, K., Derrick, C. J., \& Mukherjee, N. (2018). The use of focus group discussion methodology: Insights from two decades of application in conversation. Methods in Ecology and Evolution, 9, 20-32. https://doi.org/ 10.1111/2041-210X.12860

Organisation for Economic Cooperation and Development. (2015). Students, computers and learning: Making the connection. PISA, OECD Publishing. https://doi.org/10.1787/9789264239555-en

Organisation for Economic Cooperation and Development. (2017). PISA 2015 results: Collaborative problem solving (Vol. 5). https://doi.org/10.1787/9789264285521-en

Oskoz, A., \& Elola, I. (2016). Digital stories: Overview. Calico Journal, 33(2), 157-173. https://doi.org/10.1558/cj.v33i2.29295

Park, H.-R. (2019). ESOL pre-service teachers' experiences and learning in completing a reflection paper and digital storytelling. Australasian Journal of Educational Technology, 35(4), 63-77. https://doi.org/10.14742/ajet.4117

Perry, M. S. (2018). 21st century skills through film production in tertiary education: A transformative assessment in a literature and media course. The Southeast Asian Journal of English Language Studies, 24(4), 214-232. https://doi.org/10.17576/3L-2018-2404-16

Prenksy, M. (2001), Digital natives, digital immigrants. On the Horizon, 9(5), 1-6. https://doi.org/10.1108/10748120110424816

Ramlo, S. (2011). Using word clouds to present Q methodology data and findings. Human Subjectivity, 9(2), 99-111. https://doi.org/10.1177/1558689807309969

Schleicher, A. (Ed.) (2012). Preparing teachers and developing school leaders for the 21st century: Lessons from around the world. OECD Publishing. https://www.oecd.org/site/eduistp2012/49850576.pdf

Schultz, P. L., \& Quinn, A. S. (2013). Lights, camera, action! Learning about management with studentproduced video assignments. Journal of Management Education, 38(2), 234-258. https://doi.org/10.1177/1052562913488371

Scott, C. L. (2015). The futures of learning 2: What kind of learning for the 21st century? UNESCO Education Research and Foresight. https://learningportal.iiep.unesco.org/en/library/the-futures-oflearning-2-what-kind-of-learning-for-the-21st-century

Shih, R.-C. (2010). Blended learning using video-based blogs: Public speaking for English as a second language students. Australasian Journal of Educational Technology, 26(6), 883-897. https://doi.org/10.14742/ajet.1048

Snelson, C. (2015). Vlogging about school on YouTube: An exploratory study. New Media \& Society, 17(3), 321-339. https://doi.org/10.1177/1461444813504271

Sousa, D. A. (2017). How the brain learns (5th ed.) Corwin.

Stalmeijer, R. E., McNaughton, N., \& Van Mook, W. (2014). Using focus groups in medical education research: AMEE guide No. 91. Medical Teacher, 36(11), 923-939. https://doi.org/10.3109/0142159X.2014.917165

Stewart, D. W., Shamdasani, P. N., \& Rook, D. W. (2007). The focus group moderator. In D. W. Steward, P. N. Shamdasani, \& D. W. Rook (Eds.), Focus groups: Theory and practice (2nd ed., pp. 96-131). SAGE Publications, Inc. https://doi.org/10.4135/9781412991841.d29

Tashakkori, A., \& Teddle, C. (2002). Handbook of mixed methods in social and behavioral research. Sage.

Teo, T. (2013). An initial development and validation of a Digital Natives Assessment Scale (DNAS). Computers \& Education, 67, 51-57. https://doi.org/10.1016/j.compedu.2013.02.012 
Trilling, B., \& Fadel, C. (2009). 21st century skills: Learning for life in our times. John Wiley \& Sons, Inc.

Volkert, D. R. (2018). Building reflection with word clouds for online RN to BSN students. National League for Nursing, 39(1), 53-54. https://doi.org/10.1097/01.NEP.0000000000000159

Vygotsky, L. S. (1978). Mind in society: The development of higher psychological processes. Harvard University Press.

Vygotsky, L. S. (1986). Thought and language. MIT Press.

Williams, A., \& Katz, L. (2001). The use of focus group methodology in education: Some theoretical and practical considerations. International Electronic Journal for Leadership in Learning, 5(3), https://journals.library.ualberta.ca/iejll/index.php/iejll/article/view/496

Withall, J. (1975). Teachers as facilitators of learning: A rationale. Journal of Teacher Education, 26(3), 261-266. https://doi/10.1177/002248717502600319

Yang, Y. T. C., \& Wu, W. C. I. (2012). Digital storytelling for enhancing student academic achievement, critical thinking, and learning motivation: A year-long experimental study. Computers \& Education, 59, 339-352. http://doi.org/10.1016/j.compedu.2011.12.012

Warschauer, M. (1996a). Comparing face-to-face and electronic discussion in the second language classroom. CALICO Journal, 13(2), 7-26. https://doi.org/10.1558/cj.v13i2-3.7-26

Warschauer, M. (1996b). Computer-assisted language learning: An introduction. In S. Fotos (Ed.), Multimedia language teaching (pp. 3-20). Logos International.

Corresponding author: Hui-Wen Huang, huiwen422@163.com

Copyright: Articles published in the Australasian Journal of Educational Technology (AJET) are available under Creative Commons Attribution Non-Commercial No Derivatives Licence (CC BY-NC-ND 4.0). Authors retain copyright in their work and grant AJET right of first publication under CC BY-NC-ND 4.0.

Please cite as: Huang, H.-W. (2021). Effects of smartphone-based collaborative vlog projects on EFL learners' speaking performance and learning engagement. Australasian Journal of Educational Technology, 37(6), 18-40. https://doi.org/10.14742/ajet.6623 


\section{Appendix}

\section{Focus group interview protocol and questions}

The purpose of the focus group interview is to understand students' perceptions of engaging in group vlog projects in English learning.

Interview protocol guide:

A. Establishing good rapport with the participants

- Greeting and expressing thankfulness for attending the interview

- Explaining the purpose of the study and the outline of the interview procedures

- Telling the interviewees that the interviewers may ask further questions to clarify some ideas from their answers

- Asking some basic questions about their role in the collaborative vlog projects this semester, such as vlog plot writer, video filming person, post-editing person, etc.

B. Interview time

Asking questions about the interviewees' perceptions of group vlog projects in general. Afterwards, asking them any thoughts about the opportunities and challenges after participating in the vlog projects. The two questions are open-ended for answering:

(1) What do you think of the opportunities you experienced from the vlog projects in English learning?

(2) What do you think of the challenges you observed from the vlog projects in English learning?

(3) What's your suggestion for improving the future vlog project?

C. Showing appreciation to the interviewees

- Expressing appreciation for their participation and asking whether the researcher can reach them if there is any information need to confirm.

- Informing the interviewees that they can check the interview transcripts if they wish. 